\title{
The birth of the
}

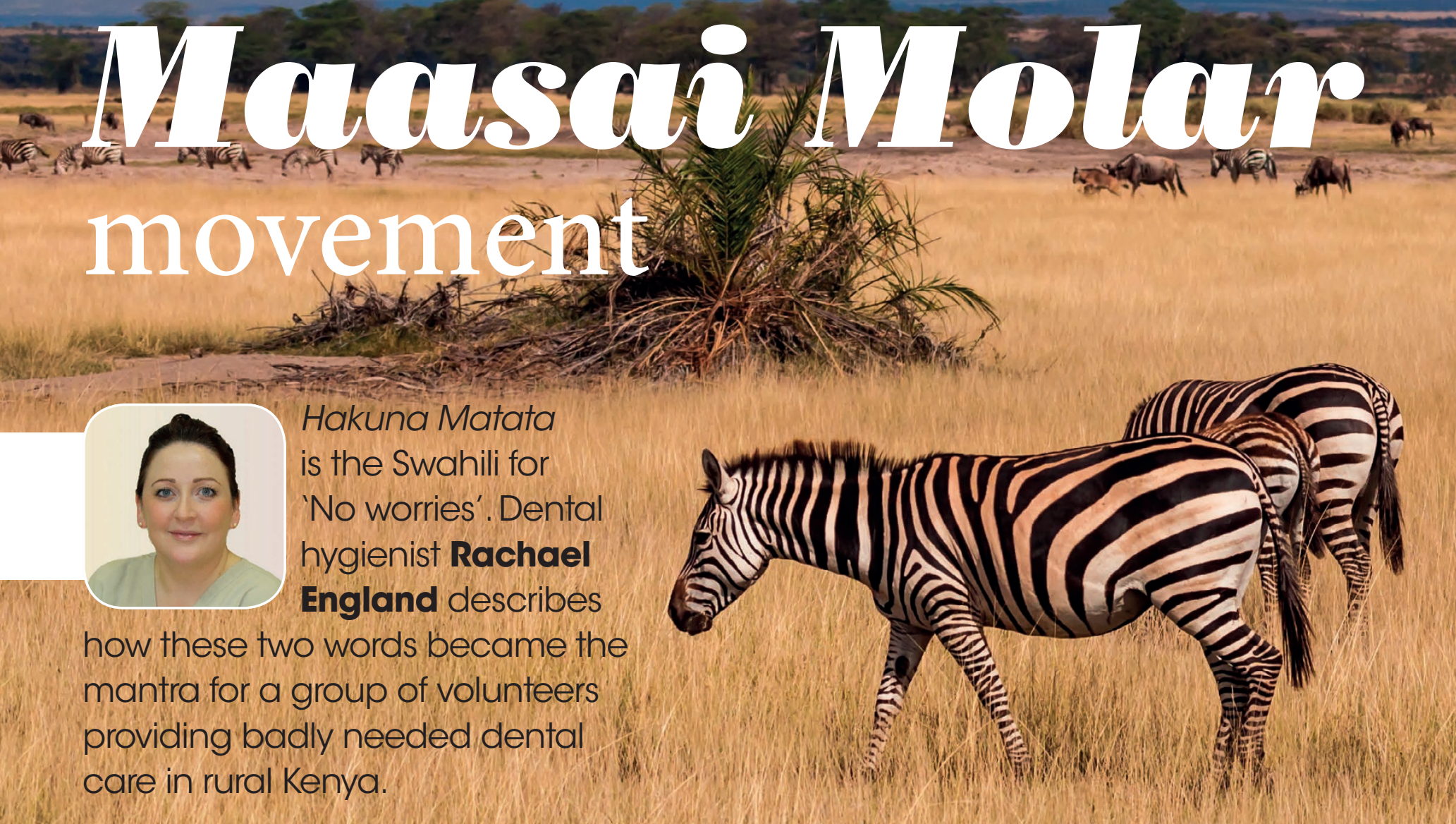

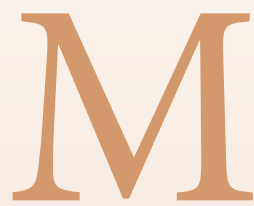

y phone beeped for the thousandth time that day. A group of us, mostly from dental backgrounds, were trying

to meet in Nairobi as the starting point for a week's volunteering in Aiotong, Kenya. This time the text was from our only dentist Dr. Jamshed Tairie and his wife Zohra, who were travelling from Amsterdam. 'Our flight has been cancelled!' they said. We were boarding soon, all I could do was furiously tweet their airline and hope they were on the next flight.

I had visited Aitong, Kenya in 2015. I carried out oral health lessons in three village schools and held a dental hygiene clinic while the dentists were busy providing pain relieving extractions and some basic fillings. Knowing the high treatment need and worrying no-one had returned to the region since, I decided to set up a return expedition myself? It couldn't be that hard...

Arriving in Nairobi we quickly cleared customs, with only a brief struggle to import 2000 toothbrushes, 2000 toothpastes and an assortment of dental materials and instruments! Seeing our guide Simi waiting was such a relief, he had an update - Jamshed and Zohra would arrive that evening and he had already arranged a taxi to bring them out to us. But, Yasmeen, joining us from Saudi Arabia, had missed her flight and wouldn't arrive until the next day!

The catchy refrain from Disney's Lion King came to mind and we told ourselves: Hakuna Matata, the Swahili for 'no worries'. We decided set up the clinic the next day as planned, and hopefully have a full team by the afternoon. Simi, our host, had worked hard to find us accommodation and got us booked into a brand new hotel, quite an upgrade from the tents we were expecting! The hotel staff at Enaitoti Hotel were absolutely amazing. Despite having opened early especially to accommodate us and having no hot water for the first part of the week, they greeted us with such hospitality, cooked three fantastic meals a day, held two parties and treated us like family. I can’t express my gratitude enough for the way they went 'above and beyond' to make sure we were happy.

After a much needed night's sleep the team rose early to set up the clinic in Aitong medical centre. Having visited before I was already aware that we would have water and electricity, but limited lighting. The electric set-up runs from solar panels on the roof but switches to a diesel-run generator from about $3 \mathrm{pm}$, costing approximately \$20 per day. Sterilisation and cross-infection can be an issue in low-income countries when carrying out humanitarian work, but careful planning by Hilary Browne meant the team were well prepared with an entire decontamination process and two pressure cookers, ensuring both clinician and patient safety.

A dental hygiene clinic was set up with 2 portable ultrasonic scalers and oral hygiene aids. Hasna Hafsi, Yasmeen Arafsha, Hanan Abdalla and Shaima Obaid bin Rabeeha carried out dental screenings, preventative treatment and prophylactic scaling for the local school children. Hanan and Yasmeenalso held fun and interactive oral health lessons for groups of children, where they sang and learned about tooth brushing and healthy snacks. Patients often request cleaning to remove the brown stains seen frequently in the Mara. This discoloration is due to the high levels of fluoride found in the ground water. Despite community efforts, filters to remove such high concentrations are expensive to maintain and local people continue to be afflicted with severe fluorosis. Unfortunately, the global trend for fizzy drink consumption and refined carbohydrates is also an issue in 




Aitong, leading to caries and according to the community doctors, also a rise in diabetes and cardiovascular disorders.

In the main surgery patients were triaged by dental hygienists Karina Carniato and Stephany Gardner. They used their full skill set to assess and anaesthetise patients ready for dental therapist Maddie Tucker and dentist Dr Jamshed Tairie to carry out basic restorative care and extractions. Zohra oversaw the surgery, tracking treatment and helping with patient care.

Outside our general volunteer Lisa Hicks, registered patients and created a basic filing system to ensure future expeditions have patient treatment records. On my previous visit, with only Simi to interpret the local language of Swahili for the whole clinic, I struggled. This time I recruited four local young men to assist in translation and clinic organisation. One of the young men, Delama, had been both deaf and mute due to a childhood illness and abandoned by his mother as a result. The whole community were able to sign language with him and he totally ran the clinic for us! He really inspired the whole team with his positive attitude and told us that despite his challenges, he has gone on to lead a fulfilled life and have three beautiful children of his own.
The first day in clinic went smoothly as word spread throughout the community that a dental team was in town. The majority of people attended with pain or broken teeth due to caries, but some children also requested removal of outstanding upper canines - which normally would undergo orthodontic treatment, an impossibility at the moment, which raised an ethical question 'should healthy teeth be removed for aesthetics?' especially in still growing teens. I advised the team to leave them in situ and we could review next time we visit if they have dropped into place any further. zebras, buffalo and cheetahs. They were also welcomed with traditional singing and dancing by the village elders at the local Maasai village of local Manyatta. Maasai are great pastoralists, living semi-nomadic lives which have remained unchanged for hundreds of years. They are easily recognised by their colourful clothes, elaborate beaded jewellery, stretched ear lobes and the absence of the lower central incisors, which are extracted in childhood. Their diet mostly consists of milk, meat, vegetables and maize, leading to low rates of dental caries and virtually no heart disease!

\section{'BY USING THE TRIAGE MODEL AND THE FULL}

\section{SKILL SET OF THE TEAM WE WERE 100\% MORE}

\section{EFFECTIVE THAN A DENTIST WORKING ALONE.}

It wasn't all work and no play for the team, Sunday, Wednesday and Thursday were spent in the Maasai Mara National Park, where they were lucky enough to see elephants, lions, leopards,
Monday and Tuesday were long days in the clinic, working from 08.30 to the last light of the day. Although it was school holidays the local Head Teacher, Mr Ndarasi Dismas had arranged 
for local children to return for the day to have a dental screening and any treatment needed. Happily about 150 children made the trip to see us, who then in a huge surprise performed songs for the team.

Many children live at the school to avoid the perilous journey walking across the Mara to reach lessons. Facilities are basic but clean and safe, with wonderful, enthusiastic teachers. The team and I will be working with the school in future to ensure more children are able to receive an education which costs $\$ 20$ per month -beyond the pocket of some families on the Mara. St. John Paul II school receives no government funding and relies solely on community support and external donors. Currently 394 children reside at the school, yet there are approximately 2000 children living in the region. Thanks to the RagstoRiches charity in the UAE we were able to distribute 270 home-
Right: Getting up close with elephants on the Maasai Mara

Main photo: Dr Jamshed and Zohra meet the Maasai Chief and his son.

Left: The team with Enaitoti staff
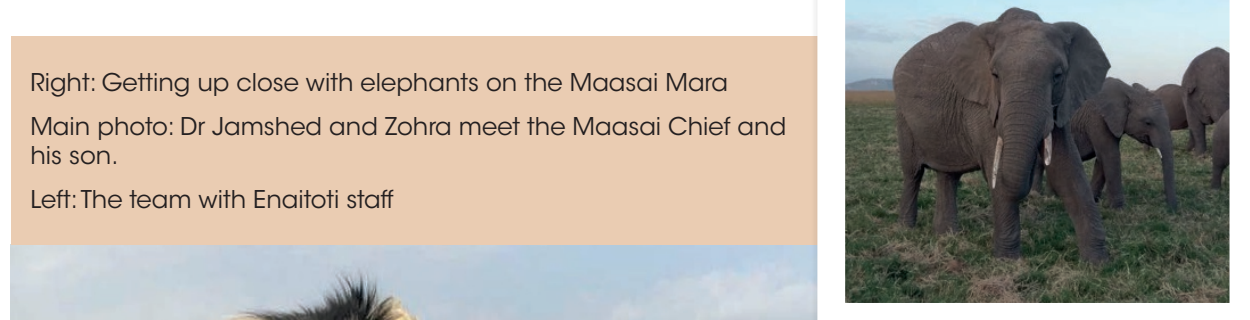

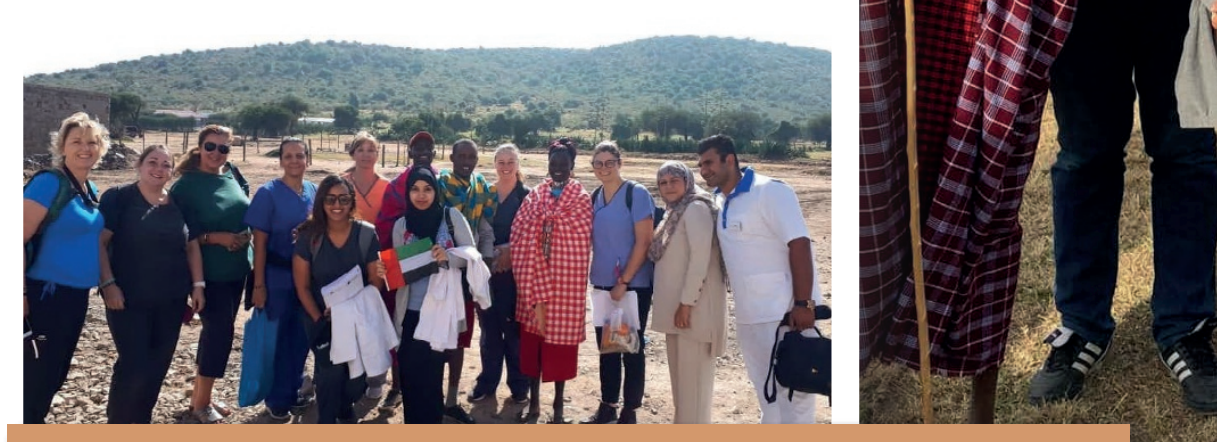

'THE GLOBAL TREND FOR FIZZY DRINK

\section{CONSUMPTION AND REFINED CARBOHYDRATES}

IS ALSO AN ISSUE IN AITONG, LEADING TO

\section{CARIES AND ACCORDING TO THE COMMUNITY}

\section{DOCTORS, ALSO A RISE IN DIABETES AND}

\section{CARDIOVASCULAR DISORDERS.'}

made sanitary kits to local girls. Ragstoriches is an amazing group of volunteers who recycle bedsheets into reuseable sanitary pads to help reduce the stigma of menstruation, allowing girls to stay in school throughout the whole year.

Clinically, the team experienced many cases of severe crowding, carious 6's in very young children and carious 8's in everyone else. Overall the clinic carried out 77 extractions, 19 fillings, 26 prophylaxis and dozens of oral health lessons. St. John Paul II school received toothbrushes and toothpaste to ensure all children would start the year able to brush twice daily.
I'm especially proud of the team for working together with limited resources to achieve so much. By using the triage model and the full skill set of the team we were $100 \%$ more effective than a dentist working alone.

The next trip for July 2019 is already in planning and I have begun to establish an organisation called 'Maasai Molar. We aim to continue visiting Aitong, but also to acquire our own clinic in the area which can employ local staff and provide mentoring for dentists trained in Nairobi. We are also open to applications from other primary healthcare professionals.
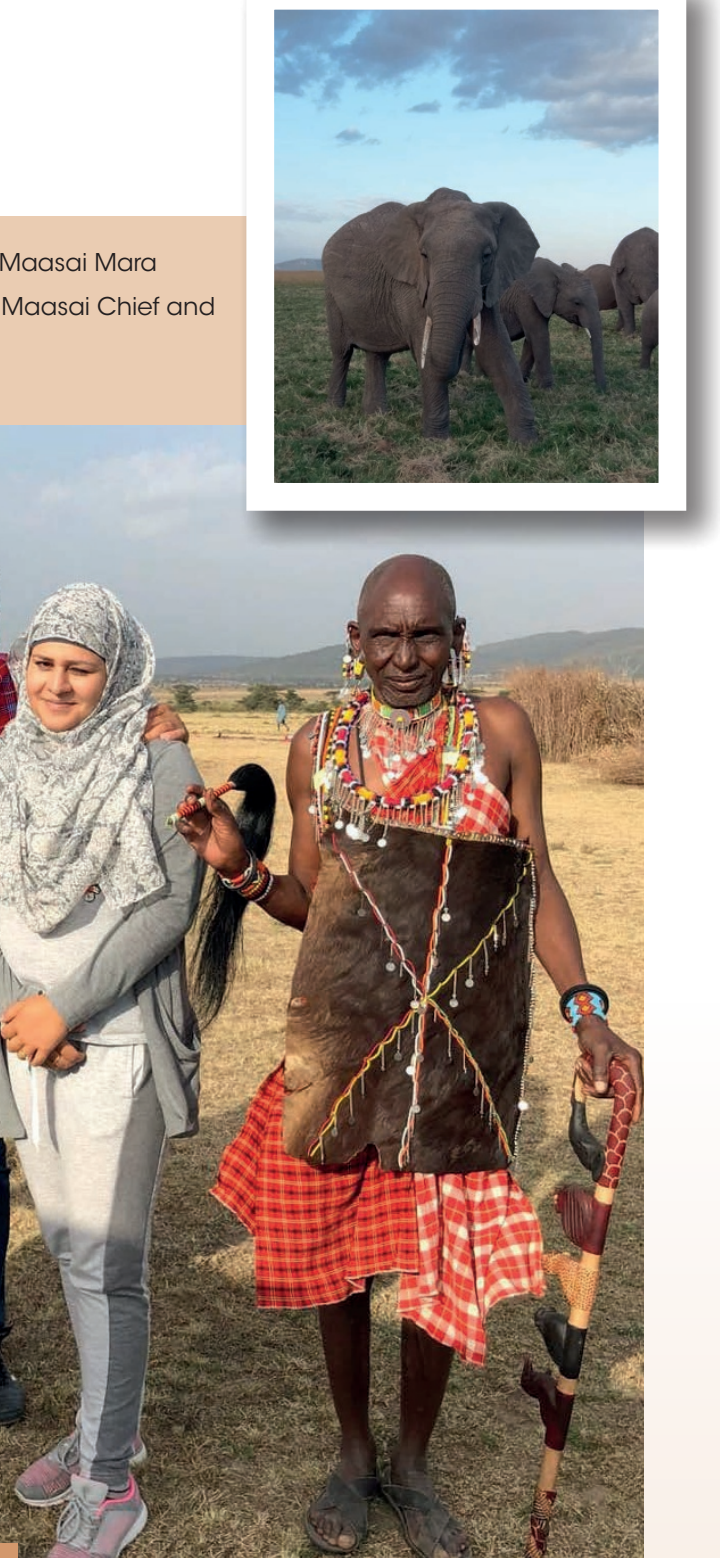

1)
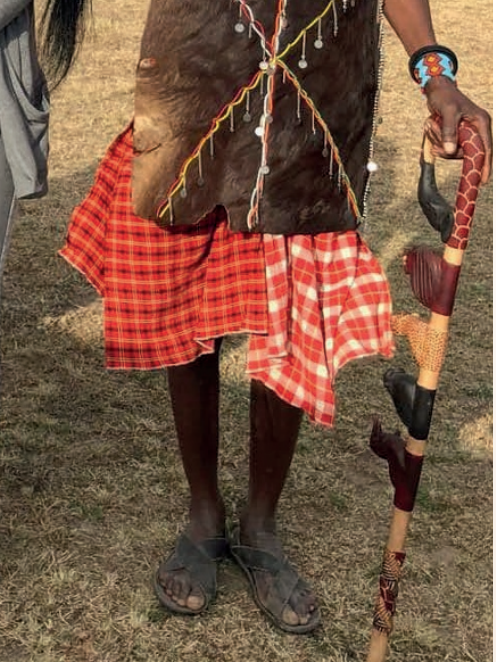